\title{
Long-term winter warming trend in the Siberian Arctic during the mid- to late Holocene
}

\author{
Hanno Meyer ${ }^{1 \star}$, Thomas Opel ${ }^{1}$, Thomas Laepple ${ }^{1}$, Alexander Yu Dereviagin ${ }^{2}$, Kirstin Hoffmann $^{1 \dagger}$ \\ and Martin Werner ${ }^{3}$
}

Relative to the past 2,000 years ${ }^{1,2}$, the Arctic region has warmed significantly over the past few decades. However, the evolution of Arctic temperatures during the rest of the Holocene is less clear. Proxy reconstructions, suggest a longterm cooling trend throughout the mid- to late Holocene $e^{3-5}$, whereas climate model simulations show only minor changes or even warming ${ }^{6-8}$. Here we present a record of the oxygen isotope composition of permafrost ice wedges from the Lena River Delta in the Siberian Arctic. The isotope values, which reflect winter season temperatures, became progressively more enriched over the past 7,000 years, reaching unprecedented levels in the past five decades. This warming trend during the mid- to late Holocene is in opposition to the cooling seen in other proxy records $s^{3,5,9}$. However, most of these existing proxy records are biased towards summer temperatures. We argue that the opposing trends are related to the seasonally different orbital forcing over this interval. Furthermore, our reconstructed trend as well as the recent maximum are consistent with the greenhouse gas forcing and climate model simulations, thus reconciling differing estimates of Arctic and northern high-latitude temperature evolution during the Holocene.

The Arctic is undergoing a pronounced and unprecedented warming, exceeding that of most other regions ${ }^{2,10}$. Its highly dynamic response to climate forcing and related feedback mechanisms make the Arctic vulnerable to future changes and a key region to study past climate variability. This is especially important owing to the global impact of Arctic water, carbon and energy balances ${ }^{11}$.

In recent years, major progress has been made in reconstructing the Arctic-wide temperature evolution of the past two millennia ${ }^{1,2}$. However, far less understood is the long-term perspective of the mid- to late Holocene ${ }^{9}$, a period with generally stable boundary conditions before industrialization and attendant impacts from increased greenhouse gas emissions ${ }^{5}$.

Existing Northern Hemisphere $(\mathrm{NH})$ proxy compilations exhibit a cooling trend over the past $7 \mathrm{kyr}$, reversed only by recent warming ${ }^{3}$, whereas climate models suggest no change or even warming over this period ${ }^{6-8}$. This contradiction may reflect the fact that Arctic temperatures are distinctly seasonal. High-latitude proxy records with an unknown or unclear seasonality assignment are difficult to interpret ${ }^{7}$. Therefore, the model-proxy mismatch ${ }^{3}$ could reflect either failure of the models or the proxies to record a specific season rather than an annual signal. The majority of Arctic palaeoclimate records are related to biological proxies (that is, tree rings and pollen) that are strongly confined to the growth period and, thus, seasonally biased towards summer conditions ${ }^{12}$. Only about $10 \%$ of all terrestrial reconstructions from recent Arctic proxy compilations $^{9,13}$ are assumed to represent winter temperatures, mostly based on pollen assemblages. However, reconstructing both summer and winter temperatures from the same pollen data set is problematic ${ }^{14}$ and strong similarities of winter and summer reconstructions - that is, from a nearby lake record ${ }^{15}$ - are probably unrealistic in a distinctly seasonal Arctic climate.

Furthermore, most Arctic proxy records stem from North America, Greenland and Scandinavia, whereas the vast Siberian Arctic is under-represented in proxy data compilations ${ }^{1,2,9,13}$. Hence, to derive a comprehensive picture of the Arctic Holocene climate variability, further information on past Siberian climate is crucial, especially for the winter season.

Permafrost as a major component of the cryosphere not only responds to climate change ${ }^{16}$, but can also be used as a climate archive to fill the knowledge gap regarding winter temperatures. Ice wedges are one of the most common types of ground ice within permafrost, and may be identified by vertically oriented foliations of the ice body. They form when thermal contraction cracks open in winter, which are periodically filled with snow melt water in spring that quickly (re)freezes at negative ground temperatures to form ice veins ${ }^{17}$. Ice wedges are, thus, considered as a climate archive for the meteorological winter (DecemberFebruary, DJF) and spring (March-May, MAM) - that is, the cold period of the year (DJFMAM; hereafter referred to as winter) - and can be studied similarly to glacier archives ${ }^{18}$, as demonstrated for the Pleistocene-Holocene transition in Alaska ${ }^{19}$. Their isotopic composition, $\delta^{18} \mathrm{O}$ (in \%o versus V-SMOW; Vienna Standard Mean Ocean Water) is interpreted as a proxy for local surface temperatures (Supplementary Information), although other processes and mechanisms (such as atmospheric transport, moisture source changes, seasonality effects of snow cover and frost cracking) might impact on the $\delta^{18} \mathrm{O}$ signal. However, both observations and isotope modelling results indicate that temperature is the primary control on $\delta^{18} \mathrm{O}$ in the study region (Supplementary Information).

In this paper, we present a stable isotope record from ice wedges, reflecting winter temperatures derived from the continuous permafrost zone in the central part of the Lena River Delta (LD; $\left.72^{\circ} 00^{\prime}-72^{\circ} 45^{\prime} \mathrm{N}, 125^{\circ} 00^{\prime}-127^{\circ} 15^{\prime} \mathrm{E}\right)$ in Northern Siberia. Permafrost in this area is cold (about $-11^{\circ} \mathrm{C}$ ) and extends to a

\footnotetext{
${ }^{1}$ Alfred Wegener Institute, Helmholtz Centre for Polar and Marine Research, Periglacial Research Section, Telegrafenberg A43, 14473 Potsdam, Germany. ${ }^{2}$ Moscow State University, Department of Geocryology, Faculty of Geology, Vorob'evy Gory, 119899 Moscow, Russia. ${ }^{3}$ Alfred Wegener Institute, Helmholtz Centre for Polar and Marine Research, Paleoclimate Dynamics Section, Bussestraße 24, 27570 Bremerhaven, Germany. ${ }^{\dagger}$ Present address: Centre for Ice and Climate, Niels Bohr Institute, University of Copenhagen, Juliane Maries Vej 30, 2100 Copenhagen, Denmark. ${ }^{*}$--mail: Hanno.Meyer@awi.de
} 

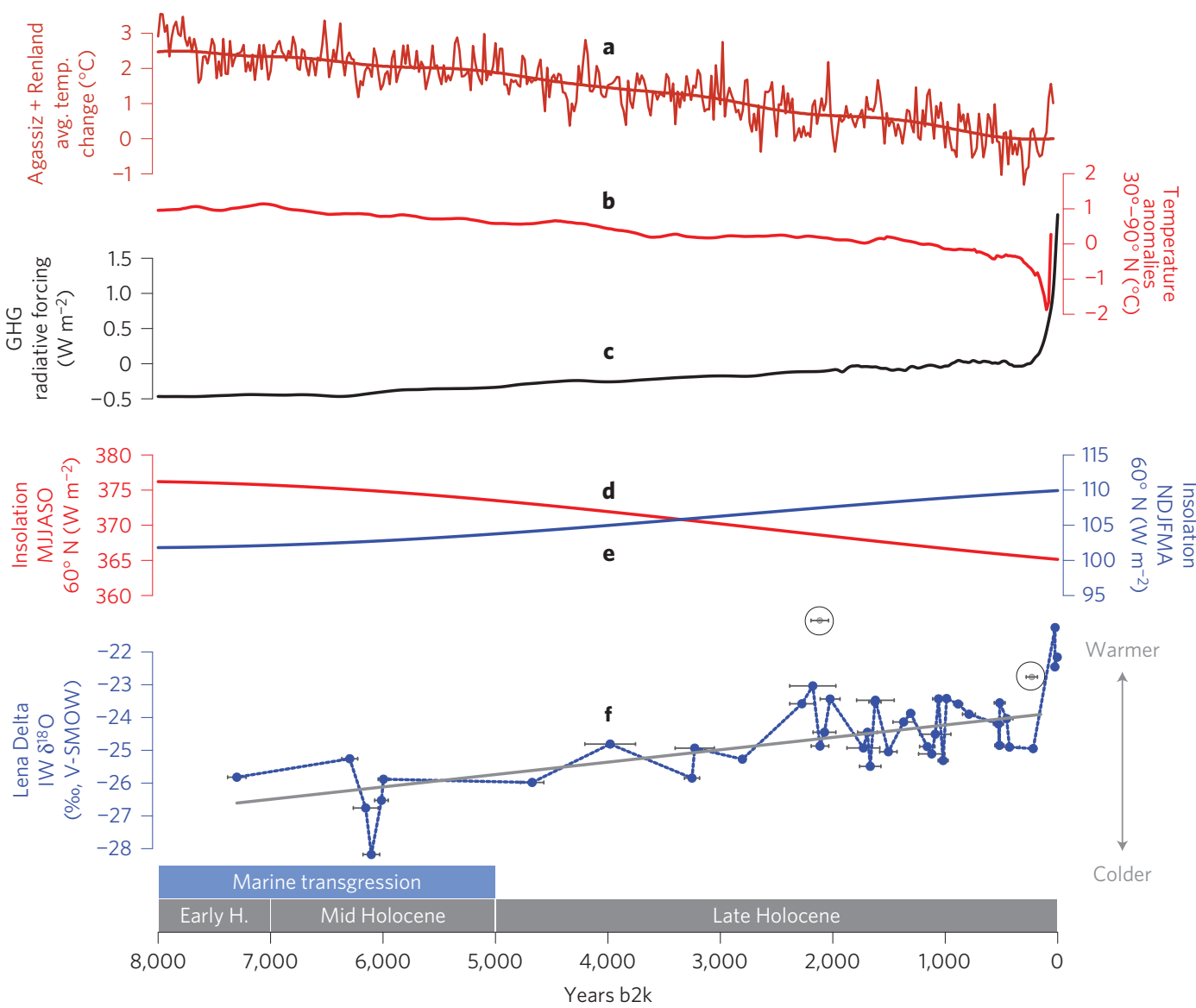

Figure 1 | Temperature and climate forcing time series for the past eight millennia, showing different seasonal trends. a, Annual temperature change from Agassiz and Renland ice cores ${ }^{4}$. b. Reconstructed temperature anomalies 30-90 N (ref. 3). c, Greenhouse gas radiative forcing ${ }^{26}$. d,e, Mean insolation at $60^{\circ} \mathrm{N}$ for the warm (MJJASO) and the cold season (NDJFMA; ref. 24). f, Lena Delta $\delta^{18} \mathrm{O}$ record with warming trend (grey line) and uncertainty of radiocarbon dating (highest posterior density range). Further indicated is the period of marine transgression on the Laptev Sea Shelf ${ }^{27}$. Two samples (encircled) have not been considered in calculating the Lena Delta $\delta^{18} \mathrm{O}$ warming trend (Supplementary Information).

depth of approximately $600 \mathrm{~m}$. We studied ten ice wedges from the first Lena River terrace (height $10-12 \mathrm{~m}$, above the modern floodplain) that were active from mid-Holocene to present, and three ice wedges from Holocene sediments above a Late Pleistocene ice-rich permafrost sequence ${ }^{20}$ (Ice Complex; third Lena terrace, height about $25 \mathrm{~m}$; Supplementary Fig. 1). All samples were taken at outcrops along the course of the Lena River channels. The ice-wedge samples-each of about $1.5 \mathrm{~cm}$ width-comprised generally fewer than ten single ice veins (that is, frost crack infill events) and were melted and analysed for stable oxygen isotopes. Considering frost cracking is a repetitive process, but not necessarily occurring every winter, we relate each ice-wedge sample to a period of about 20 years (Supplementary Information). To establish an accurate chronology for our $\delta^{18} \mathrm{O}$ record, we used only ice-wedge samples that included sufficient organic material for AMS ${ }^{14} \mathrm{C}$ dating. In total, 42 samples (first Lena River terrace: 37; top of Ice Complex: 5) have been used to generate a stacked $\delta^{18} \mathrm{O}$ record from central LD ice wedges, resulting in the first Arctic mid- to late Holocene ice-wedge-based winter temperature reconstruction (Fig. 1). As a modern analogue, we also sampled 12 actively growing recent ice wedges, which we relate to the past ten years (Supplementary Information).

The AMS ${ }^{14} \mathrm{C}$ ages indicate continuous ice-wedge formation between about $7.3 \mathrm{kyr}$ cal b2k (before AD 2000; Supplementary Table 1) and today. The $\mathrm{LD}$ record exhibits a significant $\delta^{18} \mathrm{O}$ increase over the past $7 \mathrm{kyr}$ (Fig. 1), interpreted as a mid- to late Holocene winter warming trend (until AD 1850; $+(0.45 \pm 0.16) \% / 1,000 \mathrm{yr})$, followed by an unprecedented recent
Arctic winter warming. This Holocene warming trend is in clear contrast to most other Arctic and $\mathrm{NH}$ proxy compilations $\mathrm{s}^{5,7,13}$, including the Greenland temperature record both from oxygen isotopes $^{4}$ and boreholes ${ }^{21}$ as well as the most recent $\mathrm{NH}\left(30^{\circ}\right.$ to $90^{\circ} \mathrm{N}$ ) multi-proxy reconstructions ${ }^{3}$, which show a cooling since the Early Holocene (Fig. 1). The reason for these different trends has to be related either to regionally different behaviour of the LD region and/or the season of temperature signal preserved in ice wedges (winter).

To assess the influence of seasonality and to understand the discrepancy between our LD record and the existing temperature reconstructions, we analysed the ensemble of state-of-the-art climate model simulations performed in the Paleoclimate Modelling Intercomparison Project Phase III (PMIP3; ref. 22) for the mid-Holocene (6 kyr b2k) and the pre-industrial (PI, AD 1850).

At our study site, most model simulations (10 out of 14) show a winter warming, which is in line with our ice-wedge record (Fig. 2). In contrast, in summer (JJA) all models, and in the annual mean most models (11 out of 14) show a cooling.

This seasonally differing temperature pattern extends over large parts of the polar regions ${ }^{23}$ and is therefore also relevant for other Arctic and NH reconstructions ${ }^{2,3}$.

The opposite summer and winter temperature changes in both proxy data and models $s^{6-8}$ can be explained by seasonally different orbital forcing. Whereas the $60^{\circ} \mathrm{N}$ insolation from May to October decreased after about $9 \mathrm{kyr} \mathrm{b} 2 \mathrm{k}$, the insolation relevant for the recording season of ice wedges (NDJFMA, see Methods) increased 

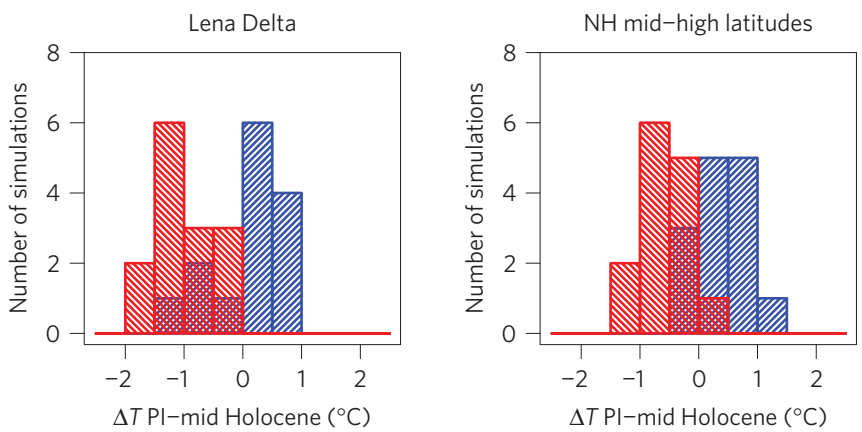

Figure $\mathbf{2}$ | Simulated temperature change between pre-industrial and mid-Holocene. Distribution of temperature differences between pre-industrial (PI) and mid-Holocene (6 kyr b2k) simulations from PMIP3 model simulations: (left) Lena Delta, (right) $\mathrm{NH}$ mid-high latitudes $\left(30^{\circ}-90^{\circ} \mathrm{N}\right)$. Blue bars represent the ice-wedge recording season (DJFMAM) and red bars summer (JJA).

over the same period by a comparable amount ${ }^{24}$ (Fig. 1). The annual mean insolation north of $45^{\circ} \mathrm{N}$ decreased following the changes of the Earth's axis tilt. This effect is strongest towards the poles and is in line with the cooling at the Greenland borehole sites ${ }^{21}$.

In addition to the direct response to insolation changes, nonlinear feedbacks caused by ocean, sea-ice and land-cover changes shape the Arctic temperature evolution during the mid-Holocene $e^{25}$. These feedbacks are more important in meteorological winter (DJF), where the PMIP3 models diverge in the sign of their temperature response (Supplementary Information), than in the remaining seasons $\mathrm{s}^{25}$. This explains why the simulated temperature spread across models in the ice-wedge winter (DJFMAM) is larger than in summer (Fig. 2).

The PMIP3 simulations probably underestimate the winter warming trend as the prescribed $\mathrm{CO}_{2}$ concentration in the model simulations was held constant, whereas atmospheric $\mathrm{CO}_{2}$ increased by $23 \mathrm{ppm}$ in the considered time interval ${ }^{6,26}$. We therefore conclude that the warming trend inferred from our ice-wedge record might include a contribution of greenhouse gas forcing to winter temperatures ${ }^{6}$, and implies a strong role of insolation forcing for Holocene Arctic temperature variability during both winter and summer.

Additionally, for the interpretation of our ice-wedge isotope record, regional Holocene environmental changes have to be considered. The Laptev Sea region experienced a marine transgression reaching its present sea level and maintaining a stable position since about $5 \mathrm{kyr}$ b2k (ref. 27). The flooding of the Laptev Sea shelf shortened the distance of our study area to the Arctic Ocean by about $400 \mathrm{~km}$. This implies a reduced continentality with lower annual temperature amplitudes that could have contributed to the winter temperatures (Fig. 1). Nonetheless, the general winter warming trend from our LD $\delta^{18} \mathrm{O}$ record remains robust when discarding samples before $5 \mathrm{kyr}$ b2k.

The majority of dated LD ice-wedge samples stem from the past $2.3 \mathrm{kyr}$ (31 AMS ${ }^{14} \mathrm{C}$ dates), allowing us to study the past $2 \mathrm{kyr}$ in more detail (Fig. 3). In this time period, the record exhibits a significant positive correlation $(r=0.59, p=0.005)$ with the multiproxy Arctic $2 \mathrm{k}$ annual temperature reconstruction ${ }^{2}$. Tuning the age model within the uncertainty of the AMS ${ }^{14} \mathrm{C}$ dates, a correlation of $r=0.8, p=0.02$ is obtained (Supplementary Information). This correlation can be attributed to similar centennial-scale variations in both records, such as a warmer period around $1 \mathrm{kyr}$ b2k, a subsequent colder phase in the past millennium (Little Ice Age) followed by a sharp warming towards the recent Arctic temperature maximum (Figs 1 and 3).

However, there are marked discrepancies between the longterm trends in the Arctic $2 \mathrm{k}$ and the LD ice-wedge records that

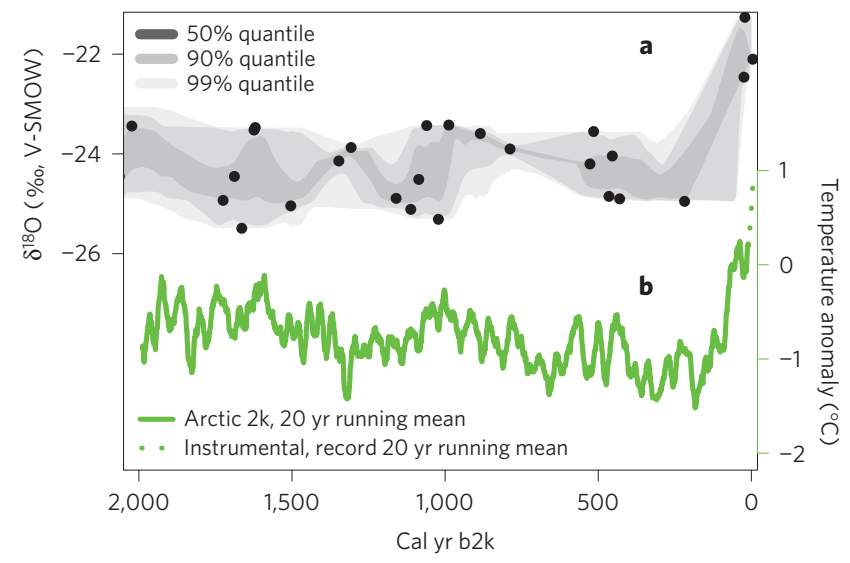

Figure 3 | Arctic temperature trends during the past two millennia.

a, Lena Delta $\delta^{18} \mathrm{O}$ record; the grey bands show the uncertainty caused by the radiocarbon dating (Methods). b. Annual Arctic temperature anomalies from PAGES $2 k$ Arctic $^{2}$ and HadCRUT3 records ${ }^{29}$.

are probably related to differences in seasonality (summer-proxydominated annual versus winter signal) and spatial distribution (Arctic-wide versus Siberia). Whereas the annual reconstruction ${ }^{2}$ exhibits a significant cooling trend before the recent warming $(0-1,850$ cal yr, $(-0.32 \pm 0.06) \mathrm{K} / 1,000 \mathrm{yr})$, our winter record shows no significant change in the same period.

The recent unprecedented warming in the LD ice-wedge record is at least of regional significance, as confirmed by an independent second detailed sampling of Holocene ice wedges at the Oyogos Yar section $\left(72.7^{\circ} \mathrm{N}, 143.5^{\circ} \mathrm{E}\right.$; Supplementary Fig. 1), also yielding the highest $\delta^{18} \mathrm{O}$ values in the most recent samples for the past two millennia ${ }^{28}$.

The absolute maximum $\delta^{18} \mathrm{O}$ values, and thus the warmest winter conditions of the entire LD ice-wedge record (and also in the Arctic $2 \mathrm{k}$ ) are observed in recent times. This is in agreement with recent ice wedges showing similar $\delta^{18} \mathrm{O}$ values (Figs 1 and 3; Supplementary Information). For the past century, the radiative forcing caused by the anthropogenic increase of greenhouse gases has affected summer and winter temperatures and, thus, both the presumably summer-biased reconstructions ${ }^{1-3}$ as well as our icewedge-based winter record. As recent Arctic warming has taken place predominantly in the winter season ${ }^{11}$, the Arctic amplification is particularly pronounced in our winter reconstruction.

Our findings highlight the potential of permafrost, in particular ice wedges, as a centennial-scale mid-resolution palaeoclimate archive, and because ice wedges are strictly related to the winter season, they add new and highly relevant information on seasonal aspects of the Arctic Holocene temperature history.

\section{Methods}

Proxy-time relationship accounting for the age uncertainty. As every ice-wedge sample is dated with a separate ${ }^{14} \mathrm{C}$ measurement and the chronological order between single ice wedges is not determined by their position, age models can be constructed by repeated sampling of point estimates from the calibrated distributions of the dates (using the probability distribution from the calibration at that age). To account for and to visualize the effect of the age uncertainty on the proxy time series, 10,000 age models were constructed. For every age model a proxy curve was estimated by linearly interpolating the $\delta^{18} \mathrm{O}$ values between the observed points. Finally, the $50 \%, 90 \%$ and $99 \%$ quantiles of the $\delta^{18} \mathrm{O}$ distribution for every point in time were calculated and plotted (Fig. 3).

Correlation analysis and estimation of linear trends. As the ice-wedge record contains recent samples we first extended the Arctic $2 \mathrm{k}$ reconstruction to AD 2010 using the area-weighted HadCRUT3 record ${ }^{29}$ north of $60^{\circ} \mathrm{N}$, after aligning the Arctic $2 \mathrm{k}$ and the HadCRUT3 record in the 1961-1990 period. To compare the ice-wedge record with the extended annual Arctic $2 \mathrm{k}$ record, we calculated 20-year averages of the Arctic $2 \mathrm{k}$ record at the estimated ages of the 
ice-wedge samples. Using the 'best guess age model' corresponding to the point estimates for the ages, we obtain a correlation of 0.58 , which is highly significant ( $p=0.005$ ) even when accounting for the temporal autocorrelation (experiment with 10,000 surrogate time series using an autoregressive first-order process $\mathrm{AR}(1)$ with a lag-1 autocorrelation estimated from the Arctic $2 \mathrm{k}$ record). The correlation remains highly significant even when fully accounting for the time uncertainty (Supplementary Information). For linear trends, we provide the standard error of the slope accounting for the reduction in effective degrees of freedom caused by temporal autocorrelation.

Analysis of PMIP3 models and the insolation forcing. We analysed the monthly surface air temperature fields of 14 simulations from 13 models (Supplementary Table 2) participating in the PMIP3 project (http://pmip3.lsce.ipsl.fr). The monthly means over the supplied model years (typically more than 100) are calculated for the pre-industrial and the mid-Holocene (6 kyr b2k) simulations and the difference is analysed. We analysed the winter season, which we expect to be recorded in the ice wedges (DJFMAM), as well as the classical summer season (JJA) to represent the summer-biased proxies. To compare our record against insolation forcing, we analysed the insolation one month before the recording season (NDJFMA) to account for the local time lag between insolation and temperature response ${ }^{30}$

Received 17 July 2014; accepted 16 December 2014; published online 26 January 2015

\section{References}

1. Kaufman, D. S. et al. Recent warming reverses long-term Arctic cooling. Science 325, 1236-1239 (2009).

2. PAGES $2 \mathrm{k}$ Consortium. Continental-scale temperature variability during the past two millennia. Nature Geosci. 6, 339-346 (2013).

3. Marcott, S. A., Shakun, J. D., Clark, P. U. \& Mix, A. C. A reconstruction of regional and global temperature for the past 11,300 years. Science 339, 1198-1201 (2013).

4. Vinther, B. M. et al. Holocene thinning of the Greenland ice sheet. Nature 461, 385-388 (2009)

5. Wanner, H. et al. Mid- to Late Holocene climate change: An overview. Quat. Sci. Rev. 27, 1791-1828 (2008).

6. Timm, O. \& Timmermann, A. Simulation of the last 21,000 years using accelerated transient boundary conditions. J. Clim. 20, 4377-4401 (2007)

7. Lohmann, G., Pfeiffer, M., Laepple, T., Leduc, G. \& Kim, J. H. A model-data comparison of the Holocene global sea surface temperature evolution. Clim. Past 9, 1807-1839 (2013).

8. Braconnot, P. et al. Results of PMIP2 coupled simulations of the Mid-Holocene and Last Glacial Maximum-Part 1: Experiments and large-scale features. Clim. Past 3, 261-277 (2007).

9. Sundqvist, H. S. et al. Arctic Holocene proxy climate database-new approaches to assessing geochronological accuracy and encoding climate variables. Clim. Past 10, 1605-1631 (2014).

10. Serreze, M. C. \& Barry, R. G. Processes and impacts of Arctic amplification: A research synthesis. Glob. Planet. Change 77, 85-96 (2011).

11. Snow, Water, Ice and Permafrost in the Arctic (SWIPA): Climate Change and the Cryosphere (Arctic Monitoring and Assessment Programme, 2011); http://www.amap.no/documents/doc/snow-water-ice-and-permafrostin-the-arctic-swipa-climate-change-and-the-cryosphere/743

12. Miller, G. H. et al. Temperature and precipitation history of the Arctic. Quat. Sci. Rev. 29, 1679-1715 (2010).

13. Sundqvist, H. S. et al. Climate change between the mid and late Holocene in northern high latitudes-Part 1: Survey of temperature and precipitation proxy data. Clim. Past 6, 591-608 (2010).

14. Birks, H. B., Heiri, O., Seppä, H. \& Bjune, A. E. Strengths and weaknesses of quantitative climate reconstructions based on late-Quaternary biological proxies. Open Ecol. J. 3, 68-110 (2010).

15. Andreev, A. A., Klimanov, V. A. \& Sulerzhitsky, L. D. Vegetation and climate history of the Yana River lowland, Russia, during the last 6400 yr. Quat. Sci. Rev. 20, 259-266 (2001).
16. Walter, K. M., Zimov, S. A., Chanton, J. P., Verbyla, D. \& Chapin, F. S. III Methane bubbling from Siberian thaw lakes as a positive feedback to climate warming. Nature 443, 71-75 (2006).

17. Lachenbruch, A. H. Mechanics of Thermal Contraction Cracks and Ice-Wedge Polygons in Permafrost (Geological Society of America Special Paper 70, 1962)

18. Mackay, J. R. Oxygen isotope variations in permafrost, Tuktoyaktuk Peninsula area, Northwest Territories. Current Res. B 83-1B, 67-74 (1983).

19. Meyer, H. et al. Permafrost evidence for severe winter cooling during the Younger Dryas in northern Alaska. Geophys. Res. Lett. 37, L03501 (2010).

20. Schwamborn, G., Rachold, V. \& Grigoriev, M. N. Late Quaternary sedimentation history of the Lena Delta. Quat. Intern. 89, 119-134 (2002).

21. Dahl-Jensen, D. et al. Past temperatures directly from the Greenland ice sheet. Science 282, 268-271 (1998).

22. Braconnot, P. et al. Evaluation of climate models using palaeoclimatic data. Nature Clim. Change 2, 417-424 (2012).

23. Mairesse, A., Goosse, H., Mathiot, P., Wanner, H. \& Dubinkina, S. Investigating the consistency between proxy-based reconstructions and climate models using data assimilation: A mid-Holocene case study. Clim. Past 9, 2741-2757 (2013).

24. Laskar, J. et al. A long-term numerical solution for the insolation quantities of the Earth. Astron. Astrophys. 428, 261-285 (2004).

25. Zhang, Q. et al. Climate change between the mid and late Holocene in northern high latitudes; Part 2: Model-data comparisons. Clim. Past 6, 609-626 (2010)

26. Joos, F. \& Spahni, R. Rates of change in natural and anthropogenic radiative forcing over the past 20,000 years. Proc. Natl Acad. Sci. USA 105, 1425-1430 (2008)

27. Bauch, H. A. et al. Chronology of the Holocene transgression at the North Siberian margin. Glob. Planet. Change 31, 125-139 (2001).

28. Opel, T., Dereviagin, A. Y., Meyer, H., Schirrmeister, L. \& Wetterich, S. Palaeoclimatic information from stable water isotopes of Holocene ice wedges on the Dmitrii Laptev Strait, northeast Siberia, Russia. Permafrost Periglacial Process. 22, 84-100 (2011).

29. Brohan, P., Kennedy, J. J., Harris, I., Tett, S. F. B. \& Jones, P. D. Uncertainty estimates in regional and global observed temperature changes: A new data set from 1850. J. Geophys. Res. 111, D12106 (2006).

30. Laepple, T. \& Lohmann, G. Seasonal cycle as template for climate variability on astronomical time scales. Paleoceanography 24, PA4201 (2009).

\section{Acknowledgements}

We greatly acknowledge numerous people involved in field and lab work, in particular L. Schoenicke and C. Springer (AWI Potsdam) for stable isotope analyses. We acknowledge the World Climate Research Programme's Working Group on Coupled Modelling, which is responsible for CMIP, and we thank the climate modelling groups for producing and making available their model output. For CMIP the US Department of Energy's Programme for Climate Model Diagnosis and Intercomparison provided coordinating support and led development of software infrastructure in partnership with the Global Organisation for Earth System Science Portals. The PMIP3 Data archives are supported by CEA and CNRS. This paper is a contribution to the research programme PACES II, Topic 3 of the Alfred Wegener Institute, Helmholtz Centre for Polar and Marine Research and to the Eurasian Arctic Ice 4k project (grant OP 217/2-1 by Deutsche Forschungsgemeinschaft awarded to T.O.). T.L. was supported by the Initiative and Networking Fund of the Helmholtz Association (grant VG-900NH).

\section{Author contributions}

H.M., A.Y.D. and T.O. designed the study and carried out the fieldwork. H.M. and K.H. performed the stable water isotope analyses on ice wedges. H.M. wrote the first draft of the manuscript. T.L. performed the statistical analysis of the isotope and climate model data. All authors contributed to data interpretation and the preparation of the final manuscript.

\section{Additional information}

Supplementary information is available in the online version of the paper. Reprints and permissions information is available online at www.nature.com/reprints.

Correspondence and requests for materials should be addressed to H.M.

\section{Competing financial interests}

The authors declare no competing financial interests. 